\title{
Studi Struktur Komunitas Fitoplankton Di Danau Batur, Kecamatan Kintamani, Kabupaten Bangli, Provinsi Bali
}

\author{
Komang Gustika Nirasari, I Wayan Arya, Sang Ayu Made Putri Suryani \\ Program Studi Manajemen Sumber Daya Perairan, Fakultas Pertanian, Universitas Warmadewa, \\ E-mail: gustikanr@gmail.com
}

\begin{abstract}
Lake Batur is the largest lake in Bali with many activities surrounding that will have great impact on fertility of the lake. One key factor in the fertility of the lake is phytoplankton. Abundance of phytoplankton in the waters affected by several environmental parameters. This research was conducted at Lake Batur, Kintamani district, Bangli Regency, in February 2014. Study is to measure the composition, abundance, diversity, uniformity and dominance of phytoplankton in the waters, measuring parameters and aquatic physical chemistry. The diversity of phytoplankton species found in Lake Batur are 5 class consists of 20 genera. Phytoplankton abundance ranged from 232370-336325 ind/l are eutrophic lake. Phytoplankton diversity index were included in diversity, uniformity index is included in the low uniformity, dominance index showed no dominance. Physical and chemical parameters of water still shows a good value so that the waters of Lake Batur contamination has not occurred.
\end{abstract}

Keywords: Community Structure, Phytoplankton, Lake Batur.

\section{Pendahuluan}

Danau Batur adalah danau terbesar dari empat danau yang ada di Bali. Danau Batur merupakan danau kaldera aktif dengan luas 15,9 km2 (Bapedalda Provinsi Bali, 2004). Danau ini dimanfaatkan oleh penduduk sekitar sebagai sumber air pertanian, tempat budidaya ikan seperti Kantong Jaring Apung (KJA), pelabuhan dan sebagai tempat wisata. Aktivitas tersebut memberikan dampak yang signifikan terhadap perairan Danau Batur. Fitoplankton merupakan komponen populasi pembentuk komunitas dari suatu ekosistem yang dapat menggambarkan kondisi suatu perairan. Struktur komunitas merupakan kumpulan individu dari beberapa jenis atau spesies yang saling berinteraksi dan terorganisir dalam suatu zonasi tertentu. Menurut Odum (1971) komunitas adalah kumpulan populasi yang hidup pada suatu lingkungan atau habitat tertentu. Fitoplankton merupakan dasar dari mata rantai pakan di perairan. Kelimpahan fitoplankton di suatu perairan dipengaruhi oleh beberapa parameter lingkungan dan karakteristik fisiologisnya.

Rumusan masalah yang dapat dirumuskan dari latar belakang diatas, sebagai berikut 1).Bagaimana struktur komunitas fitoplankton dilihat dari indeks-indeks biologis seperti komposisi, kelimpahan, keanekargaman, keseragaman dan dominasi, 2). Bagaimana kualitas air Danau Batur dilihat dari beberapa parameter fisika kimia yaitu suhu, kecerahan, $\mathrm{pH}, \mathrm{DO}$, Nitrat dan $\mathrm{BOD}_{5}$ yang berkaitan dengan fitoplankton. Penelitian ini bertujuan untuk mengetahui struktur komunitas fitoplankton yang meliputi komposisi, kelimpahan, keanekaragaman, keseragaman dan dominasi fitoplankton pada perairan Danau Batur dan mengetahui kualitas perairan Danau Batur dengan beberapa parameter fisika kimia yaitu suhu, kecerahan, $\mathrm{pH}, \mathrm{DO}$, Nitrat dan BOD5 perairan.

\section{Bahan dan Metode}

Metode yang digunakan dalam penelitian ini adalah metode deskriptif yaitu menganalisis data dan mendeskripsikan hasil penelitian. Hasil dari penelitian ini berupa hasil pengamatan kualitas dari perairan danau Batur dan struktur komunitas fitoplanktonnya. Pengamatan menggunakan pengamatan secara 
visual dan juga menggunakan alat bantu berupa mikroskop binokuler. Data yang diambil berupa data primer dan data sekunder. Data primer diperoleh dengan observasi yaitu pengamatan langsung dan partisipasi yaitu ikut langsung dalam kegiatan pengambilan data. Sedangkan data sekunder diperoleh dari literatur-literatur yang terkait dengan masalah yang ada.

Penelitian ini dilaksanakan pada 26 Februari - 3 Maret 2014. Saat penelitian berlangsung Danau Batur sedang mengalami musim penghujan. Penelitian dibagi menjadi dua kegiatan yaitu penelitian di lapangan dan penelitian di laboratorium. Penelitian lapangan dilakukan di Danau Batur, Kecamatan Kintamani, Kabupaten Bangli. Sedangkan penelitian laboratorium dilakukan di Laboratorium Fakultas Pertanian, Universitas Warmadewa. Danau Batur dipilih sebagai lokasi penelitian dengan menggunakan metode purposive sampling yaitu penentuan sampel dengan sengaja berdasarkan beberapa pertimbangan. Jumlah stasiun pada penelitian terdiri dari 4 stasiun yang dibagi berdasarkan pemanfaatan daerah perairan tersebut.

\section{Hasil dan Pembahasan}

Komposisi fitoplankton di perairan Danau Batur selama pengamatan terdiri dari 5 kelas yang terdiri dari 20 genus yaitu kelas Bacillariophyceae (5 genus), Cyanophyceae (7 genus), Clorophyceae (5 genus), Dinophyceae (1 genus) dan Diatomae (2 genus). Seluruh kelas terdapat pada setiap stasiun dan substasiunnya, ini menggambarkan penyebaran fitoplankton pada perairan Danau Batur merata. Setiap jenis fitoplankton yang berbeda dalam kelompok filum tersebut mempunyai respon yang berbeda-beda terhadap kondisi perairan, sehingga komposisi jenis fitoplankton bervariasi dari satu tempat ke tempat lain (Welch, 1952).

Tabel 1

Komposisi Fitoplankton

\begin{tabular}{ccccc}
\hline \multirow{2}{*}{ Kelas } & \multicolumn{4}{c}{ Jumlah Genus } \\
\cline { 2 - 5 } & Stasiun I & Stasiun II & Stasiun III & Stasiun IV \\
\hline Bacillariophyceae & 4 & 4 & 5 & 3 \\
Cyanophyceae & 5 & 5 & 5 & 5 \\
Clorophyceae & 4 & 3 & 1 & 1 \\
Diatomae & 2 & 2 & 2 & 1 \\
Dinophyceae & 1 & 1 & 1 & 1 \\
\hline
\end{tabular}

Kelimpahan fitoplankton pada perairan Danau Batur yang tertera dalam Tabel 1, menunjukkan nilai yang sangat tinggi. Perairan yang memiliki kelimpahan fitoplankton antara 0-2000 ind/1 maka perairan itu bersifat oligotrofik, kelimpahan fitoplankton antara 2000-15000 ind/1 bersifat mesotrofik dan bersifat eutrofik mempunyai kelimpahan lebih besar dai 15000ind/l (Landner,1976). Sehingga perairan Danau Batur masuk dalam perairan yang bersifat eutrofik. Kelimpahan yang tinggi disebabkan oleh adanya unsur hara yang masuk kedalam perairan dan adanya proses up-welling.

Tabel 2

Kelimpahan Fitoplankton (ind/l) dan Indeks-indeks biologi fitoplankton

\begin{tabular}{ccccc}
\hline Indeks Biologi & \multicolumn{4}{c}{ Stasiun } \\
\cline { 2 - 5 } & I & II & III & IV \\
\hline Kelimpahan & 232.370 & 304.527 & 336.325 & 259.366 \\
Indeks Keanekaragaman & 2.06 & 2.05 & 2.03 & 1.73 \\
Indeks Keseragaman & 0.50 & 0.47 & 0.45 & 0.41 \\
Indeks Dominasi & 0.16 & 0.15 & 0.15 & 0.22 \\
\hline
\end{tabular}


Sumber : Diolah dari Data Primer, Tahun 2014

Indeks keanekaragaman fitoplankton di perairan Danau Batur pada pengamatan Februari 2014 berkisar antara 1,73-2,06. Nilai tersebut berdasarkan kriteria nilai indeks keanekaragaman Mason (1981) termasuk dalam keanekaragaman sedang. Kondisi ini mencerminkan biota yang mudah berubah hanya dengan mengalami pengaruh lingkungan yang relatif kecil. Variasi nilai keanekaragaman fitoplankton pada perairan Danau Batur tertera pada Tabel 2.

Berbanding terbalik dengan keanekaragaman, rata-rata indeks keseragaman pada pengamatan Februari 2014 di perairan Danau Batur berkisar antara 0,41-0,50 (Tabel 2). Berdasarkan dengan kriteria nilai indeks keseragaman Mason (1981), perairan Danau Batur memiliki nilai keseragaman yang rendah. Hal ini menggambarkan kekayaan individu yang dimiliki masing-masing spesies sangat jauh berbeda artinya penyebaran individu setiap jenisnya tidak sama. Penyebaran jenis fitoplankton yang tidak sama pada setiap stasiun menunjukkan pengaruh yang terjadi pada setiap stasiunnya berbeda. Diduga hanya jenis fitoplankton tertentu yang mampu hidup pada toleran kualitas perairan disetiap stasiunnya.

Nilai indeks dominasi yang ditunjukkan pada Tabel 2 pada pengamatan di perairan Danau Batur berkisar antara $0,15-0,22$, berarti nilai dominasi pada perairan Danau Batur mendeketaki nol (0). Jika nilai indeks dominasi mendekati nilai nol (0) maka dalam struktur komunitas fitoplankton yang diamati tidak adanya spesies yang secara ekstrim mendominasi spesies lainnya. Kondisi ini menunjukkan struktur komunitas yang stabil, kondisi lingkungan yang cukup prima dan tidak terjadi tekanan ekologis terhadap biota di habitat bersangkutan.

Hasil pengukuran parameter kualitas perairan yang dilakukan di perairan Danau Batur pada hari Rabu, tanggal 26 Februari 2014 tertera pada Tabel 3.

\section{Tabel 3}

Nilai Parameter Kualitas Perairan pada perairan Danau Batur

\begin{tabular}{cccccc}
\hline PARAMETER & Stasiun I & Stasiun II & Stasiun III & Stasiun IV & Kisaran Toleransi \\
\hline Suhu $\left({ }^{0} \mathrm{C}\right)$ & 22 & 23 & 23 & 23 & $20-30$ \\
Kecerahan $(\mathrm{m})$ & 1,75 & 2,4 & 1,8 & 1,8 & \\
Nitrat $(\mathrm{mg} / \mathrm{l})$ & 1,04 & 0,98 & 0,87 & 0,98 & $0,9-3,5$ \\
pH & 8 & 7 & 7 & 7 & $7-8,5$ \\
DO $(\mathrm{ppm})$ & 8.40 & 9.88 & 10.87 & 7.41 & $5<$ \\
$\mathrm{BOD}_{5}(\mathrm{ppm})$ & 4.18 & 5.35 & 5.36 & 2.67 & $0-10$ \\
\hline
\end{tabular}

*Hasil pengukuran tahun 2013 oleh Badan Lingkungan Hidup Provinsi Bali

Sumber : Diolah dari Data Primer, Tahun 2014

Hasil pengukuran suhu pada perairan Danau Batur disetiap stasiunnya dapat dilihat pada Tabel 3, yang berkisar antara 22-23 C . Seperti yang dijelaskan oleh Ray dan Rao (1967) bahwa kisaran suhu optimum untuk perkembangan fitoplankton berkisar antara $20^{\circ} \mathrm{C}-30^{\circ} \mathrm{C}$. Sehingga suhu permukaan pada perairan Danau Batur merupakan suhu yang optimum bagi perkembangan fitoplankton dan biota air lainnya. Kecerahan suatu perairan menunjukan intensitas cahaya matahari yang dapat menembus kedalaman suatu perairan yang berguna untuk proses fotosintesis. Cahaya yang masuk ke badan perairan menjadi faktor pemicu produktivitas primer perairan, selain ketersediaan unsur hara. Kecerahan suatu perairan dipengaruhi oleh kandungan lumpur, kandungan plankton dan kandungan unsur terlarut lainnya. Kandungan nitrat $\left(\mathrm{NO}_{3}^{-}\right)$pada perairan Danau Batur berkisar antara 0,87-1,04 ppm. Keberadaan nitrat di perairan sangat dipengaruhi oleh buangan yang berasal dari industri, bahan peledak, piroteknik dan pemupukan. Hasil pengukuran derajat keasaman pada perairan Danau Batur berkisar 
antara 7-8. Nilai rata-rata setiap stasiun tidak jauh berbeda, hanya pada stasiun I yang merupakan daerah pelabuhan memiliki nilai $\mathrm{pH}$ yang tertinggi yaitu 8 yang berarti perairan tersebut termasuk dalam basa. Stasiun lainnya menunjukan nilai 7 yang berarti derajat keasamannya normal. Pada perairan Danau Batur kandungan oksigen berkisar antara 7,41-10,87 ppm. Oksigen terlarut dalam perairan ini termasuk sangat tinggi, hal ini terjadi karena kecerahan yang tinggi membuat proses fotosintesis berlangsung dengan baik. Hasil pengukuran $\mathrm{BOD}_{5}$ perairan Danau Batur berkisar antara 2,67-5.36 dengan kisaran optimum 0-10 ppm. BOD tinggi menunjukkan bahwa jumlah oksigen yang dibutuhkan oleh mikroorganisme untuk mengoksidasi bahan organik dalam air tersebut tinggi. Banyaknya mikroorganisme yang tumbuh dalam air disebabkan banyaknya makanan yang tersedia (bahan organik), oleh karena itu secara tidak langsung BOD selalu dikaitkan dengan kadar bahan organik dalam air.

\section{Kesimpulan}

Perairan Danau Batur memiliki komposisi fitoplankton yang terdiri dari 5 kelas dengan 20 genus yaitu kelas Bacillariophyceae (5 genus), Cyanophyceae ( 7 genus), Clorophyceae (5 genus), Dinophyceae (1 genus) dan Diatomae (2 genus). Kelimpahan fitoplanktonnya temasuk tinggi dengan nilai rata-rata 232.370-336.325 ind/1. Indeks-indeks biologi fitoplankton seperti indeks keanekaragaman (H') termasuk dalam kategori sedang. Indeks keseragaman (E) tergolong rendah. Nilai indeks dominasi (C) mendekati nol (0) yang dapat dijelaskan bahwa tidak ada spesies yang mendominasi spesies yang lain. Kondisi ini mengmbarkan perairan Danau Batur dalam keadaan yang sangat subur dan stabil sedangkan dampak dari aktivitas masyarakat sekitar belum mengakibatkan pencemaran yang berarti atau berdampak negatif bagi perairan danau.

Kualitas air Danau Batur berdasarkan parameter fisika kimia berada pada kisaran batas normal. Suhu perairan berkisar antara $22-23^{\circ} \mathrm{C}, \mathrm{pH}$ perairan berkisar antara 7-8, oksigen terlarut berkisar antara 7,4110,87 ppm, kandungan nitrat berkisar antara 0,87-1,04 ppm, $\mathrm{BOD}_{5}$ berkisar antara 2,67-5,36 ppm dan kecerahan berkisar antara 1,75-2,4 m. Kondisi kualitas air seperti ini menunjukkan bahwa perairan masih dalam keadaan normal. Melihat kondisi ekologis perairan Danau Batur, saran yang dapat diberikan: bagi petani di pinggiran danau agar melakukan usaha pengendalian masuknya pupuk ke perairan untuk mencegah terjadinya eutrofikasi di danau, pembuangan limbah dari aktivitas masyarakat sekitar agar tidak berlebihan, meminimalkan kebocoran bahan bakar dan oli pada kapal motor, pemberian pakan yang proposional dan tepat waktu pada Kantong Jaring Apung sehingga tidak terjadi sisa pakan yang terbuang ke perairan.

\section{Referensi}

Bapedalda Provinsi Bali. (2004). Profil Danau Batur. Http://limnologi.lipi.go.id/danau/profil.php. diakses 12 Desember 2013.

Odum, E. P. (1971). Fundamentals of Ecology. A Third Edition. Philadelphia, London, Toronto: W.B. Soundes Company.

Welch, P. S. (1952). Limnology. Second Edition. New York: Toronto Publisher, Dubuque. Iowa.

Ray, P. \&. Rao, N.G.S. (1969). Density of Freshwater Diatom in Relation to ome Phsycochemical Condition of Water. Blachistar. p:35-65.

Mason, C.F. (1981). Biology Freshwater Pollution. Second Edition. New York: Longman Scientific and Technical.

Landner, L. (1976). Eutrophication of Lake. Causes, Effects and Means for Control, with Emphasis on Lake Rehabilitation. Stockholm, Sweeden: WHO-Regional Office for Europe. ICP/CEP 210. 